npj|Primary Care Respiratory Medicine

\title{
CORRIGENDUM
}

\section{Building capacity to improve respiratory care: the education strategy of the International Primary Care Respiratory Group 2014-2020}

Juliet McDonnell, Jaime Correia de Sousa, Noel Baxter, Hilary Pinnock, Miguel Román-Rodríguez, Thys van der Molen and Sian Williams

npj Primary Care Respiratory Medicine (2014) 24, 14096; doi:10.1038/npjpcrm.2014.96; published online 16 October 2014

Correction to: npj Primary Care Respiratory Medicine (2014) 24, 14072; doi:10.1038/npjpcrm.2014.72; published online 25 September 2014

Since the online publication of the above article, it has been noted that the names of the second and fifth authors were published incorrectly. The correct names are given above. The corrected article appears online together with this corrigendum.

The authors would like to apologise for this error. 